\title{
DUNE EROSION ABOVE REVETMENTS
}

\author{
Jaap van Thiel de Vries ${ }^{12}$
}

\begin{abstract}
In a situation with a narrow dune, the dune base can be protected with a revetment to reduce dune erosion during extreme events. To quantify the effects of a revetment on storm impact, the functionality of the numerical storm impact model XBeach (Roelvink et al., 2009) is extended to account for the complex morphodynamics around revetments. Here the focus is on dune erosion above revetments, which is simulated with a simple avalanching algorithm that is triggered by the combined runup of short waves and long waves. The simulated runup statistics depend on the incident wave groupiness and associated long wave variance.
\end{abstract}

Keywords: Dune erosion, revetments, runup, wave groupiness, long waves

\section{INTRODUCTION}

A substantial part of the world's coastline consists of sandy beaches and dunes, which act as a natural sea defense for the hinterland. In populated areas these sandy systems are sometimes reinforced against storm impact by non-erodible structures such as a seawall that separates a boulevard from the main beach or a dune revetment that protects the dune base against erosion during storms.

Especially in populated areas there is a need to have insight in the safety against flooding for which numerical models can be a valuable tool. The presence of a structure complicates a safety assessment since the classical dune erosion process observed at an undisturbed beach profile changes.

During a storm surge the water level rises and the beach is flooded. For a classical sandy profile with dunes (see Figure 1; left panel) big storm waves can reach the dune face and impact it causing episodically slumping. The sand released from the dunes falls on the beach and acts as a sediment source for the coastal profile. Since during storms the surf is usually dissipative it are mostly wave group generated long waves that reach the dune face, trigger a slump and transport released sand from the swash towards the (inner) surf. In the inner surf intense (short) wave breaking takes place that causes high sediment suspensions and an intense undertow, which generates a large offshore transport capacity. Further seaward sediment starts to settle and a new coastal profile develops that better fits the extreme hydrodynamic conditions.
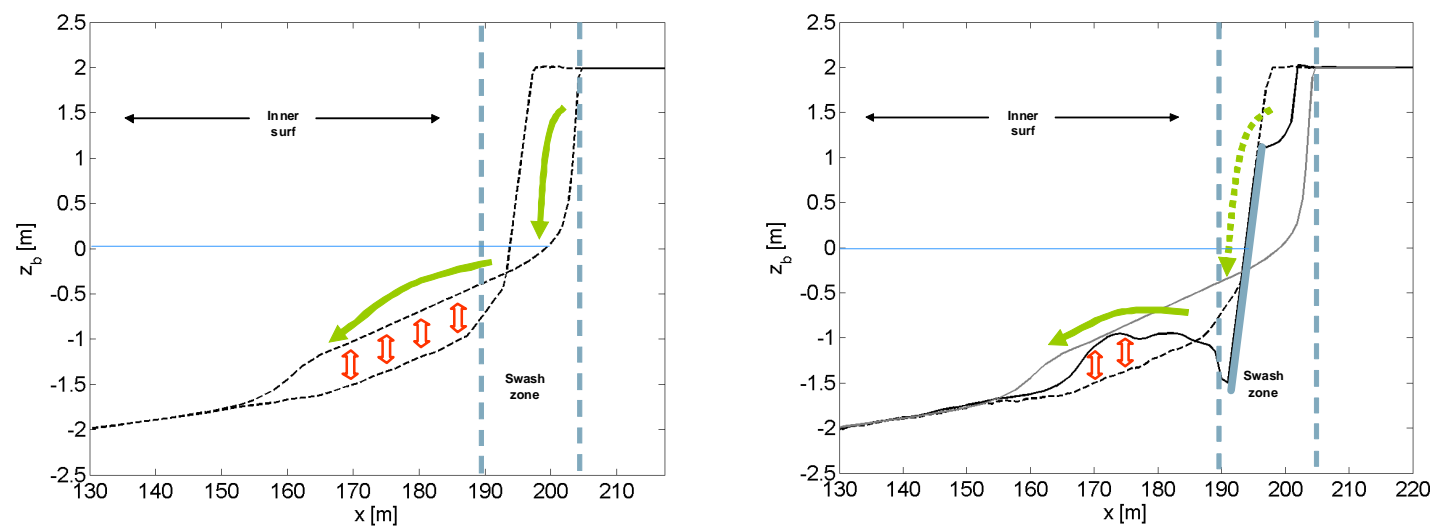

Figure 1: Morphological response during a storm surge for a sandy coastal profile (left panel) and a coastal profile with a dune revetment that partly protects the dune face (right panel).

In the presence of a structure, the process of dune erosion and associated coastal profile evolution is strongly affected both in cross-shore (see Figure 1; right panel) and in longshore direction. In crossshore direction the dune face can be (partly) protected by a revetment. The effect of such a revetment on the morphodynamics can best be evaluated by considering a fully protected dune face (seawall). In

\footnotetext{
${ }^{1}$ Deltares, Rotterdamseweg 185, 2629 HD, Delft, The Netherlands

2 Fac. of Civil Eng. and Geosciences, Dep. of Hydr. Eng., Delft University of Technology, Stevinweg 1, 2628 CN, Delft,

The Netherlands
} 
this case the sediment supply from the dune is completely blocked whereas the initial offshore transport capacity in front of the revetment remains intact. As a result the bed near the revetments toe starts to erode and a scour hole develops. For stability, the revetment should be designed in such a way that the scour depth does not exceed the foot of the revetment.

Considering a situation with a partly protected dune face the sediment supply from the dunes is partly reduced. The cross-shore profile evolution in front of the revetment mainly depends on the fraction of wave runup that exceeds the revetments height. The higher this fraction, the larger the sediment supply (erosion) from the dunes to the beach and the more the cross-shore profile evolution will correspond to classic sandy profile with dune erosion.

Besides, the effect of a revetment on the cross-shore profile also longshore effects are expected. At the transition from a revetment, dike or seawall to a fully sandy system and visa versa longshore gradients in wave height transformation and thus in associated wave set-up and longshore flows are expected. As a result a longshore sediment transport gradient is expected to be present (see Van Geer et al., these proceedings and de Vries et al., 2012), which causes additional dune erosion and a reduction in scour depth near the revetment..

In this paper the storm impact model XBeach as decribed in Roelvink et al. (2009) is extended such that the interaction with non-erodible dune revetments can be assessed. To this end an inventory of physical processes around a revetment is made where we distinguish between the scouring at the toe of the revetment and the potential erosion above the revetment. Considering the modelling the focus in this paper will be on simulating the erosion above revetments for which the required model adaptations in XBeach will be discussed. The updated model is applied to a series of large scale flume tests assessing revetments of different height. The paper ends with conclusions and discussion.

\section{Scour near revetments}

As discussed there are two morphological effects of dune revetments on the coastal profile. At the toe of the revetment a scour hole may develop and depending on the relative height of the revetment there can be erosion above the revetment. Both effects will be discussed in more detail. The amount of scour at the revetments toe can vary considerably (Summer and Fredsoe, 2002) and depends on whether:

1. waves are breaking before reaching the revetment

2. waves break, reflect or overtop the seawall

3. the sediment properties in front of the seawall (which will affect the sand mobility and the wave boundary layer) .

For the dune revetments studied in this paper (see model application section) waves are breaking (spilling) before they reach the seawall. In addition the seawalls studied will be relatively steep (1:1.8) such that incoming waves will not break on the revetment itself but will partly reflect and partly overtop it (depending on the height of the revetment). Since normative storm surge conditions are studied in this paper the mode of sand transport will be suspended and the wave boundary layer can be characterized as rough. Given these boundary conditions the scour characteristics for non-overtopping structures will according to Summer and Fredsoe (2002) depend on:

1. the type of wave breaking, which is a function of the offshore wave steepness versus the beach slope (here spilling breakers are expected).

2. the revetments location, which will affect the (initial) water depth at the revetments toe, the cross-shore distance from the breakpoint to the revetments and the penetration depth of the wave breaking induced turbulence at the revetment.

3. the sediment properties, which will affect the suspension properties in front of the revetment toe.

When waves overtop a revetment the return flow properties and the water depth are the most important variables (Nishimura et al., 1978). The water that flows back over the revetment enters the water as a jet that may cause additional scouring depending on the penetration depth.

\section{Erosion above revetments}

Erosion of the dune occurs when the dune face is subject to wave impact and is not protected (i.e. by a revetment). The interaction between the sandy dune face and swash is complex and depends on the geotechnical properties of the dune sand and the hydraulic loads. For the classical process of dune erosion (without any structures present) this results in episodically slumping of the dune face. The 
process of slumping can be mimicked with aggregated models (discussed in i.e Fisher and Overton (1984), Larson et al., 2004, Roelvink et al., 2009 and Palmsten and Holman, 2011), however the physical processes are not yet fully understood. Observations during large scale dune erosion tests in a flume (Van Gent et al., 2008) revealed that the physical interaction between dune face and swash can change as a storm surge progresses. In these laboratory tests waves initially ran over the sandy dune face resulting in drag based erosion (see Van Thiel de Vries et al, 2007). As a result of this erosion a scarp develops and waves do no longer runup the dune face but will start to impact it. The erosion rate was then found to be related to the amount of momentum absorbed by the dune face.

The presence of a revetment will further complicate the interaction between dune face and swash. The frequency and strength of wave impacts that reach the dune face will depend on the relative height of the revetment with respect to the runup distribution and the horizontal distance of the sandy dune scarp to the revetments top. Assuming the revetment stays in place (and does not collapse), a berm type platform will develop between the top of the revetment and the scarp, which will affect the runup height of the waves (TAW, 2002) and the impact of this runup on the sandy scarp.

Finally it is remarked that there is a strong feedback between the bed evolution in front of revetment and the erosion above it. The profile evolution (scouring) in front of the revetment will affect the runup characteristics (i.e relative contribution of short waves and long waves to runup) and thus the erosion rate above the revetment. On the other hand sand eroded from the dune is transported over the revetment and will (partly) deposit in front of the revetment, thus again influencing runup characteristics.

\section{MODEL IMPLEMENTATION}

The objective is to further develop the storm impact model XBeach such that the morphodynamics around a hard revetment can be (better) described. In this paper the focus is on erosion above revetments rather than the scouring in front of it.

The main philosophy of the XBeach model is that near dune hydrodynamics during storm surge conditions are dominated by wave group generated long waves, which can be solved for with the socalled surf beat approach (i.e. Roelvink et al, 1993). For a detailed model description reference is made to Roelvink et al., 2009 or the XBeach manual, that can be downloaded at xbeach.org. Here the model description will focus on how 1) hard structures can be defined in the model and 2) short wave runup is incorporated to simulate the morphodynamics of the dune face.

To take into account non-erodible elements like a revetment the sediment availability throughout the model domain needs to be specified and should be limited in areas where a structure is at the surface. In Xbeach sediment transport is simulated with an advection diffusion equation for sediment, which reads:

$$
\frac{\partial h C}{\partial t}+\frac{\partial h C u^{E}}{\partial x}+\frac{\partial h C v^{E}}{\partial y}+\frac{\partial}{\partial x}\left(D_{s} h \frac{\partial C}{\partial x}\right)+\frac{\partial}{\partial y}\left(D_{s} h \frac{\partial C}{\partial y}\right)=S=\frac{h C_{e q}-h C}{T_{s}}
$$

In which $C$ is the sediment concentration, $h$ is water depth and $D_{\mathrm{s}}$ is the sediment diffusion coefficient. The most right term acts as a sediment source term and takes into account sediment entrainment and deposition. The net change in sediment concentration depends on the difference between the equilibrium sediment concentration $\left(C_{e q}\right)$, the actual sediment concentration $C$ and an adaptation time scale $T_{s}$, which is expressed as $T_{s}=\gamma_{\mathrm{w}} h / w_{s}$, where $\gamma_{\mathrm{w}}$ is calibration coefficient default set to 0.2 and $w_{s}$ is the sediment fall velocity.

When a hard structure comes at the surface the net sediment source (sum of entrainment and deposition) is limited such that the sediment thickness that is still available on top of the hard layer $\left(h_{\text {struct }}\right)$ is not exceeded:

$$
S=\min \left(\frac{h_{s t r u c t}}{\partial t}\left(1-n_{p}\right), \frac{h C_{e q}-h C}{T_{s}}\right)
$$

The source term limiter directly affects sediment transports in the presence of non-erodible structures and thus simulated bed level changes. Bed level changes are obtained with: 


$$
\left(1-n_{p}\right) \frac{\partial z_{b}}{\partial t}+f_{m o r}\left(\frac{\partial S_{x}}{\partial x}+\frac{\partial S_{y}}{\partial y}\right)=0
$$

Where $n_{p}$ is porosity, $z_{b}$ is the bed level elevation, $f_{m o r}$ is a morphological acceleration factor, and $S_{x}$ and $S_{y}$ are transports components in cross-shore and alongshore direction respectively.

To simulate classical dune erosion and more specific the episodically slumping of the dune face under wave impact, the model includes a simple avalanching algorithm. An avalanche occurs when a critical bed slope is exceeded:

$$
\frac{\partial z_{b}}{\partial x}>m_{c r}
$$

In the model this critical slope is smaller for inundated areas (0.3) than for dry areas (1.0), which results in an erosion mechanism where waves runup and impact the dune face, thus wetting dry points that are therefore more prone to slumping. This rather simple approach works well for storms conditions at sandy coasts where near dune hydrodynamics and thus runup are dominated by long waves (Roelvink et al, 2009, Van Thiel de Vries et al, 2009). However, in situations with a dune revetment the water depth in front of a structure is usually substantially larger (less dissipative conditions) and short waves will likely contribute substantially to the net runup level.

To simulate the erosion above a dune revetment that partly protects the dunes base, the effect of both short wave runup and long wave runup need to be incorporated. Whereas the long wave water motion and associated runup are solved for with the NSWE (momentum conservative scheme for drying and flooding according to Stelling and Duinmeijer, (2003)), the short wave runup is not. The model uses the so called surf beat approach and only solves for the envelope of the incoming short wave groups. This means the short wave runup is not implicitly solved for and therefore is estimated with a simple runup formula that is comparable to the runup formulas applied in the safety assessments of dikes in the Netherlands (TAW 2002):

$$
R=\gamma_{\text {runup }} H_{r m s} \cos (\varphi) \min (\xi, 2.3)
$$

Where $R$ is the short wave runup level, $\gamma_{\text {runup }}$ is a calibration factor, $H_{r m s}$ is the wave height at the toe of the structure and $\varphi$ is the phase in the runup cycle which depends on the radian frequency and the actual time $(\varphi=\omega t)$. Finally, $\xi$ is the Iribarren number (Battjes, 1974), which describes the relative steepness of the incoming waves with respect to the revetment slope:

$$
\xi=\frac{\tan \alpha}{\sqrt{H_{m 0} / L_{0}}}
$$

Where $\tan \alpha$ is the structure slope and $L_{0}$ is the deep water wave length. It is remarked that in XBeach the wave height at the toe of the revetment varies due to morphodynamics and wave height variations on the wave group scale (we model the envelope of the incoming short waves). As a result a short wave runup distribution is simulated with Equation 5, which is constructed from the runup of individual waves in a random wave train. This approach is based on the hypothesis of equivalence, which was first applied by Saville (1962) and later (partly) validated by Battjes (1974). The total runup level is computed as:

$$
\eta_{t o t}=\eta_{w l}+R
$$

Where $\eta_{t o t}$ is the total runup level, $\eta_{w l}$ is the water line elevation (including long wave runup) and $R$ is the short wave runup level. 


\section{MODEL APPLICATION}

\section{Physical and numerical model setup}

To verify the implementation of hard elements and validate the short wave runup approach as described above a couple of physical model tests have been hind casted. The experiment (Steetzel, 1987) includes five model tests from which the first three will be discussed in this paper. The experiment was carried out in the Deltaflume (230m length, $5 \mathrm{~m}$ wide, $7 \mathrm{~m}$ depth), which is operated with an advanced wave paddle including active reflection compensation (ARC) and second order wave steering. Tests T1, T2, T3 are performed with shore normal irregular waves (Pierson Moskowitch spectrum), constant water level (4.2 meter above flume floor) and explore the morphological impact of revetments with different height (see Table 1).

\begin{tabular}{|l|c|c|c|c|c|}
\hline Test & $\begin{array}{c}\text { Height Revetment } \\
{[\mathrm{m}] \text { above max surge }}\end{array}$ & $\begin{array}{c}\text { Water level } \\
{[\mathrm{m}] \text { above floor flume }}\end{array}$ & $\begin{array}{c}\text { Hm0 } \\
{[\mathrm{m}]}\end{array}$ & $\begin{array}{c}\text { Tp } \\
{[\mathrm{s}]}\end{array}$ & $\begin{array}{c}\text { Spectrum } \\
{[-]}\end{array}$ \\
\hline T1 & 2.0 & 4.2 & 1.52 & 5.37 & PM \\
T2 & 1.2 & 4.2 & 1.52 & 5.37 & PM \\
T3 & 0.6 & 4.2 & 1.52 & 5.37 & PM \\
\hline
\end{tabular}

Table 1: Overview tests including information about revetments height and hydraulic boundary conditions.

The initial profile applied in the flume is the same for all tests and is representative for the Dutch Holland coast. All revetments have a slope of 1:1.8, which corresponds to the slope of a non-protected dune. The bottom of the revetment is at 1.7 meter below the max surge level, which is just deeper as the maximum scouring depth observed during the experiment. Several measurements were conducted including wave height (wave gauge), flow velocity (EMF's) and sediment suspensions (suction tubes) with a mobile carriage that could be positioned at varying cross-shore positions in the flume during a test. Besides wave runup time series over the (partly) protected dune face have been measured using a resistance wire. During a test the wave paddle was stopped at the end of pre-defined test intervals to record the morphological evolution with a wheel profiler. In this study measured profiles, wave height and runup are utilized to verify model performance.

A 1D XBeach model has been set-up for each model test. The grids are non-equidistant and grid resolution decreases in shoreward direction from $d x=7 \mathrm{~m}$ offshore till $d x=1 \mathrm{~m}$ in the vicinity of the revetment. Also to computational grid is designed such that the top of a revetment coincides with a grid point. Wave and flow boundary conditions are obtained from an analytical Pierson Moskowitch spectrum using the approach as described in Van Dongeren et al., (2003). Parameter settings are default except for the short wave runup calibration coefficient $\gamma_{\text {runup }}$, which is set to 0.8 in all model tests.

\section{Model Results}

Morphodynamic results for all tests are presented in Figure 2 for simulations with and without short wave runup. Starting with the profile evolution for test T1 (upper left panel), no difference with the default XBeach approach is observed. In this test the whole dune face is protected by the revetment and therefore there is (also including short wave runup) no sediment supply from the dune. The scouring process near the revetment toe is dominant and the bed elevation in front of the revetment decreases. Comparing with the measured profile evolution the scouring depth is underestimated as is the deposition zone seaward of the scour hole. The likely reason is that the model lacks some processes in the vicinity of the structure, which are hypothsized to be related to short wave reflections (not simulated in the model, however the length scale in the measured bathymetry can be related to the short wave length), the vertical momentum that is associated with rundown and the likely increases suspensions near the revetment due to turbulence production at the transition from the flat and smooth sand bed towards the rough and steep revetment.

Simulated profile evolution for test T2 with a high revetment clearly shows a different morphological response when short wave runup is accounted for. Including short wave runup the erosion above the revetment is reasonably well predicted, though the erosion volume is a bit underestimated. Analyzing the bed evolution in front of the structure shows less satisfying results and it is found that simulated morphodynamics do not correspond to the observed profile evolution, which shows again the development of a scour hole and a deposition zone seaward of it. Comparing to test 
T1, the deposition zone of test T2 extends further seaward which can be attributed to the sand supply from the dune due to erosion.
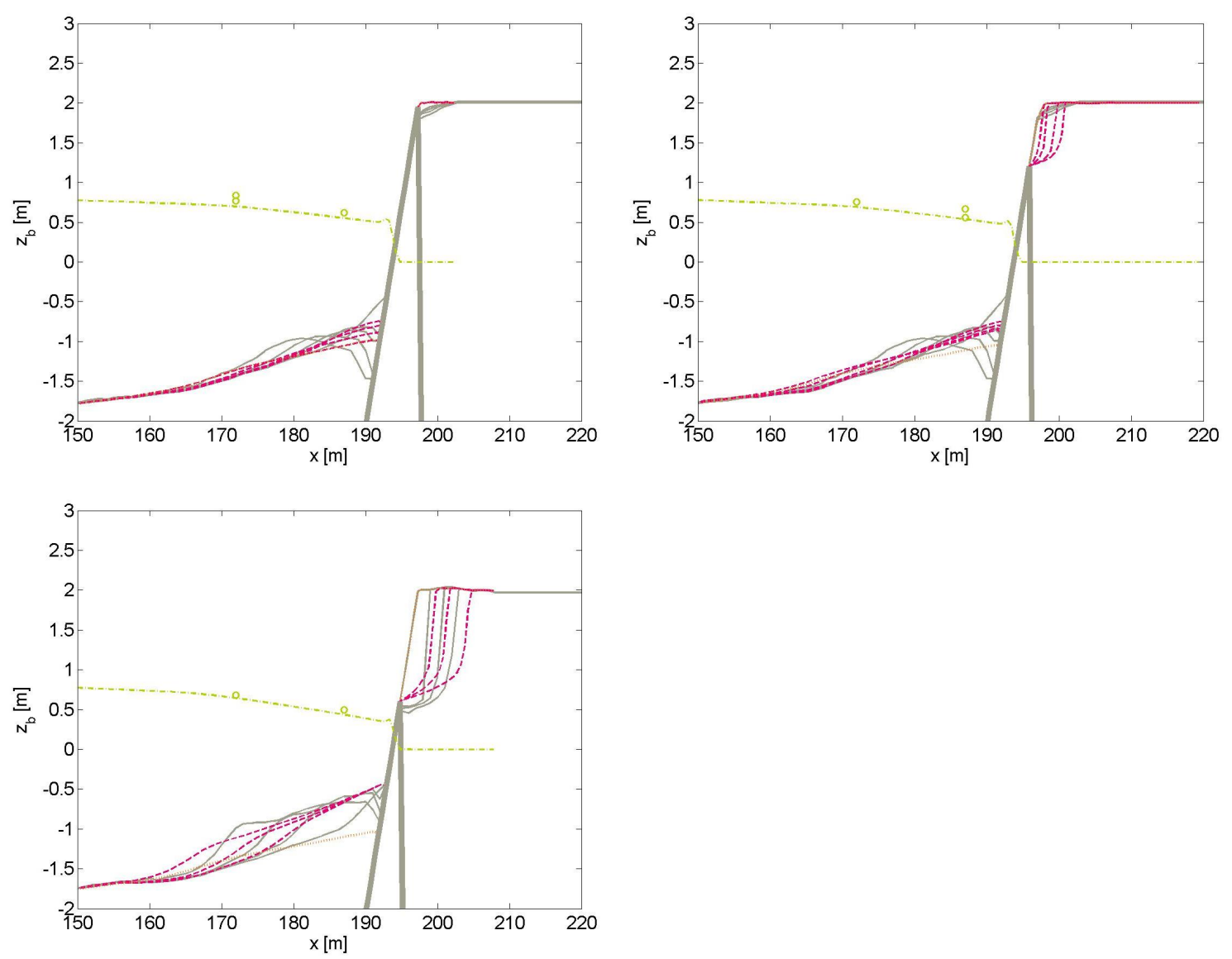

Figure 2: Comparison of measured (gray lines) profile evolution with simulated profile evolution including short wave runup (magnetta lines) and simulated final profile without short wave runup (orange line). Results are shown for test T1 (upper left panel), test T2 (upper right panel) and test T3 (lower left panel). The test averaged measured and simulated short wave height transformation is indicated by the green circles and green line respectively.

The effect of short wave runup is most pronounced in test T3 where the profile evolution substantially improves compared to the default model approach. In this test the amount of erosion is (slightly) overestimated especially at the end of the simulation. Studying the measured and simulated profile development in front of the structure it also looks much better as in the previous tests. Apparently the erosion above the revetment is such high that it dominates the profile evolution in front of the structure resulting in limited scouring in front of the revetment (though at the end of the test when erosion rates decrease a scour hole develops in the measured profiles which is not reproduced in the simulations).

To give more insight in the simulated erosion mechanism above a revetment Figure 3 compares the cross-shore sediment transport from simulated bed level changes with simulated suspension transport and transport due to avalanching for test $\mathrm{T} 3$. It is clearly visible that erosion above the revetment is caused by sediment transport associated with avalanching. All sand eroded from the dune is transported over the revetment into the water column where it is partly deposited and partly transported farther offshore. Over the revetment the sediment transport is substantial, though the sediment transport gradient is zero. In this (long wave runup) zone there is a transition from transports caused by avalanching to wave and flow driven suspended transport. 

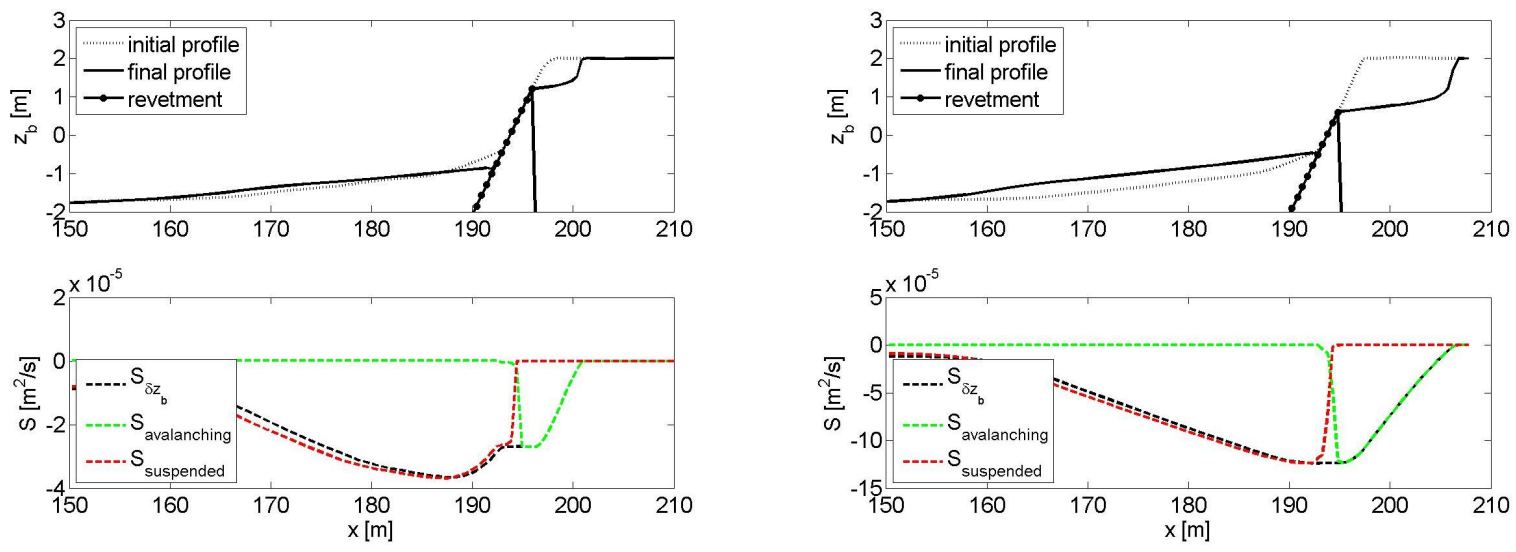

Figure 3: Simulated test averaged sediment transport from bed level changes (black) split out in sediment transport due to avalanching (green) and suspended transport (red).

\section{Comparison with runup measurements}

Presented results reveal that including short wave runup improves model performance for revetments that partly protect the dune face. However, it is also found that the model tends to underestimate erosion above high revetments (test T2) and tends to overestimate erosion above low revetments. To obtain more insight in this model behavior the simulated and measured runup statistics will be analyzed in more detail.

The measured and simulated runup statistics are shown in Figure 4 for test T3 which was found to have the most qualified runup measurements. It is remarked that at the beginning of test T2 and test T3 the simulated runup statistics are expected to be similar since the initial profile is the same in all tests. Looking at the initial runup statistics (upper left panel) it is found that measured runup distribution is substantial broader (steeper slope) than the simulated runup distribution. The runup for the highest waves is underestimated whereas the runup for the smaller waves is overestimated. This likely explains the underestimation of erosion in test T2 with the higher revetment, which is mainly susceptible to the higher runup events.

Further into the test, the runup distribution has substantially changed and becomes narrower; the slope of the black line decreases and corresponds much better to the slope (width) of the simulated runup distribution (lower left panel Figure 4). This can likely be explained by the foreshore development near the revetment where a sand berm develops just offshore of the scour pit. The sand bar will cause more intense wave breaking, which reduces the local width of the wave height distribution (wave breaking affects especially the tail of the distribution Battjes, 1985) and thus associated runup.

During the remaining of test T3 the width of the simulated runup distribution (slope of blue line w.r.t slope black line) looks much better. However, the magnitude of simulated runup levels is over predicted. At the end of the test there is a fairly good agreement between measured and simulated runup statistics (lower right panel). The overestimation of the runup levels during a significant part of the test likely explains why erosion in test $\mathrm{T} 3$ is too much.

The simulated total runup distribution can be split out in a short wave part and a long wave part. The short wave runup decreases during a tests whereas the long wave runup slightly increases making the relative contribution of long waves to the total runup statistics more important as a test progresses. 

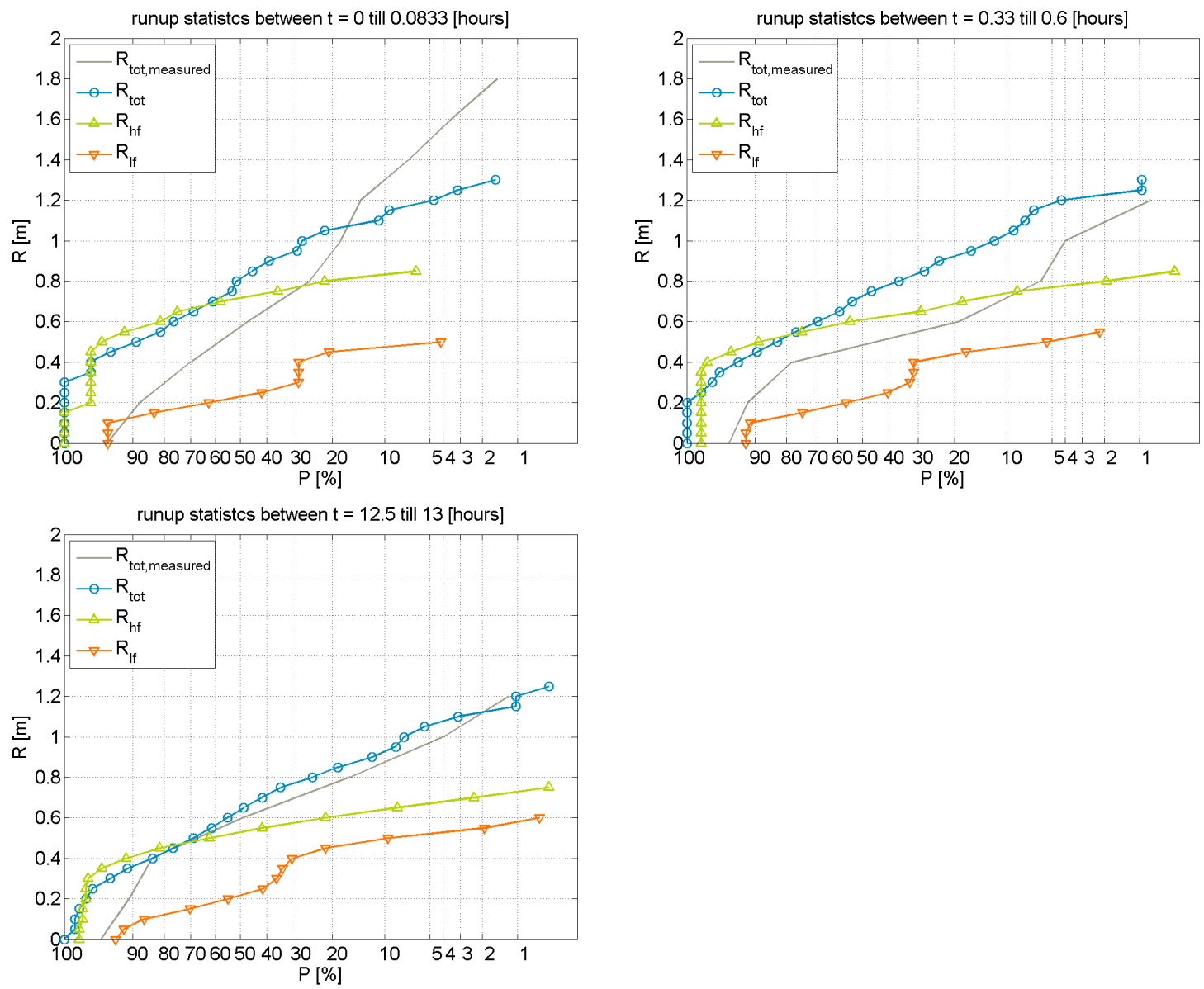

Figure 4: Measured (gray line) and simulated cumulative runup distributions during test T3 for short waves (green line), long waves (orange line) and total runup (blue line). The distributions are plotted on Rayleigh scale such that a Rayleigh distribution becomes a straight line.

\section{IMPORTANCE OF WAVE DISSIPATION FORMULATION}

In the previous section it is shown that the simulated morphodynamic response in the vicinity of a revetment strongly depends on runup caharactersitics (compare results with and without short wave runup). At this stage the simulated runup characteristics modestly correspond to observations and especially during the first part of the experiment the performance on simulated runup statistics is poor. The reason for this can be twofold; first is that simulated near dune wave height distribution is erroneous predicted (in this case the wave height distribution is expected to be too narrow; see Figure 4) and thus the associated runup distribution. Conversely the mismatch could be the result of shortcomings in the runup formulation and assumptions it is based on (i.e. validity of equivalency approach and the effect of swash-swash interactions, which are not accounted for in the present runup model).

The shape of the waveheight distribution at the revetments toe depends on how the model transforms wave groups form deep water to shallow. Dissipation due to depth induced wave breaking will be a dominant process affecting the near dune wave height distribution. Therefore the sensitivity of simulated runup statistics and morphological response near a revetment to an alternative wave dissipation formulation will be assessed. Two wave dissipation formulations will be compared. The first formulation by Roelvink (1993) is used by default in XBeach and in this formulation waves have a probability of breaking, which depends on the local wave height to depth ratio. In this formulation wave dissipation is computed as: 


$$
\begin{aligned}
& D=P_{b} D_{b} \\
& D_{b}=\alpha \rho g f H_{b}^{2} \\
& P_{b}=1-\exp \left(-\left(\frac{H_{r m s}}{\gamma h}\right)^{n}\right)
\end{aligned}
$$

Where $D$ is the local computed wave energy dissipation due to depth induced breaking, $P_{b}$ is the instantaneous probability that a wave will break and $D_{b}$ is the energy dissipation rate when a wave is breaking. $H_{b}$ is in the order of the water depth $(h), \alpha$ is a calibration coefficient set to $1, \rho$ is water density, $g$ is gravitational acceleration, $f$ is a representative frequency, $n$ and $\gamma$ are calibration coefficients set to default values (15 and 0.55 respectively).

The second dissipation formulation is described in Daly et al., 2011 and uses an advectivedeterministic approach to compute short wave dissipation due to depth induced breaking. In this formulation waves are eather breaking or not depending on a breaker criterium $\left(H_{r m s} / h>\gamma_{b}\right)$ and once a wave is breaking it keeps on breaking till another breaker criterium is no longer fulfilled $\left(H_{r m s} / h<\right.$ $\gamma_{r}$, where $\left.\gamma_{r}<\gamma_{b}\right)$. The information on whether a wave is breaking affects the breaker criterium and therefore is advected through the model domain. The advective-deterministic short wave dissipation approach reads:

$$
\begin{aligned}
& D=B D_{b} \\
& D_{b}=\alpha \rho g f H_{b}^{2} \\
& B=1, H>\gamma_{b} h \quad \text { where } \gamma_{b}=0.55 \\
& B=0, H<\gamma_{r} h \quad \text { where } \gamma_{r}=0.3
\end{aligned}
$$

Where B is the wave breaking status (either 1 for a breaking wave and 0 for a wave that is not breaking).

The impact of the short wave dissipation formulation on simulated near dune runup statistics is substantial as is indicated in Figure 5, which shows simulated runup statistics during test T3 for the default Roelvink formulation (left panels) and the advective-deterministic Daly et al. formulation (right panels). Especially in the initial phase of the test (when short wave runup is relatively more important) the simulated runup statistics improve for the advective-deterministic approach, which predicts a substantial wider runup distribution that corresponds better to observations. Surprisingly Figure 5 also reveals that not only the short wave runup statistics are affected by the short wave dissipation formulation applied, but also the long wave runup statistics change. Reason is that the short wave dissipation formulation affects the groupiness of the incident waves throughout the model domain. As a result the forcing on the water column and resulting long wave statistics will change (compare long wave runup statistics in Figure 5 for left versus right panels).

Finally Figure 6 shows how the short wave height dissipation formulation affects the morphodynamic response near the revetment. Dune face retreat above the revetment seems to be slightly better predicted when applying the Daly et al formulation whereas foreshore evolution in front of the revetment is slightly better predicted by applying the Roelvink dissipation model. Finally, it is remarked that both dissipation formulations where applied using default calibration settings and that comparison to measured near dune wave heights looks reasonable (green markers versus gree line in Figure 6). Wave heights for the Daly et al formulation are slightly underestimated and the morphodynamic results could benefit from some additional tuning. The shape of simulated runup statistics is not expected to be (strongly) affected by additional tuning. 

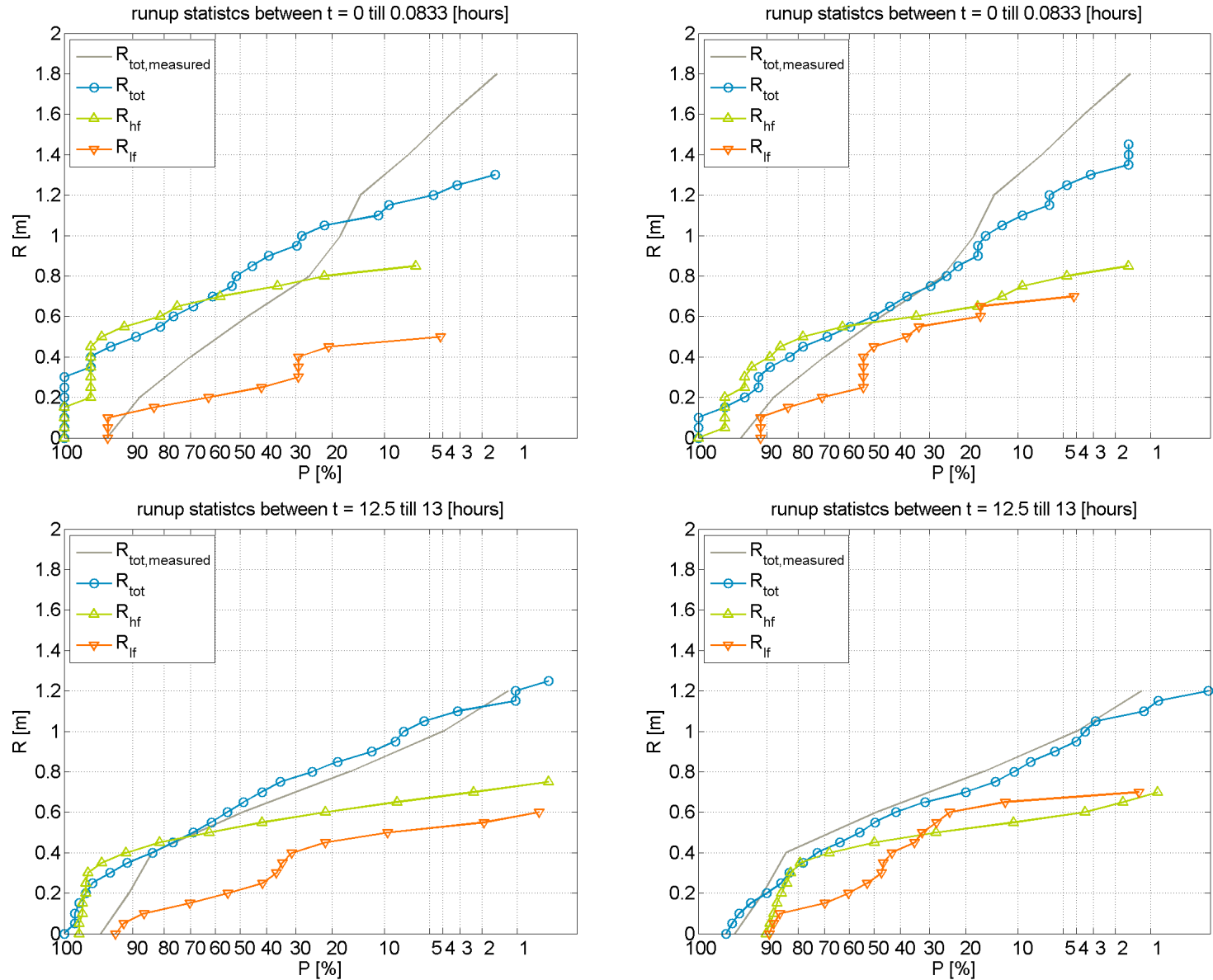

Figure 5: Initial (upper panels) and final (lower panels) runup distributions during test T3 for default short wave dissipation formulation by Roelvink, 1993 (left panels) and an advective-deterministic approach to short wave breaking as proposed by Daly et al., 2011 (right panels). Each panel shows measured (gray line) and simulated cumulative runup distributions during test $\mathrm{T3}$ for short waves (green line), long waves (orange line) and total runup (blue line). The distributions are plotted on Rayleigh scale such that a Rayleigh distribution becomes a straight line.
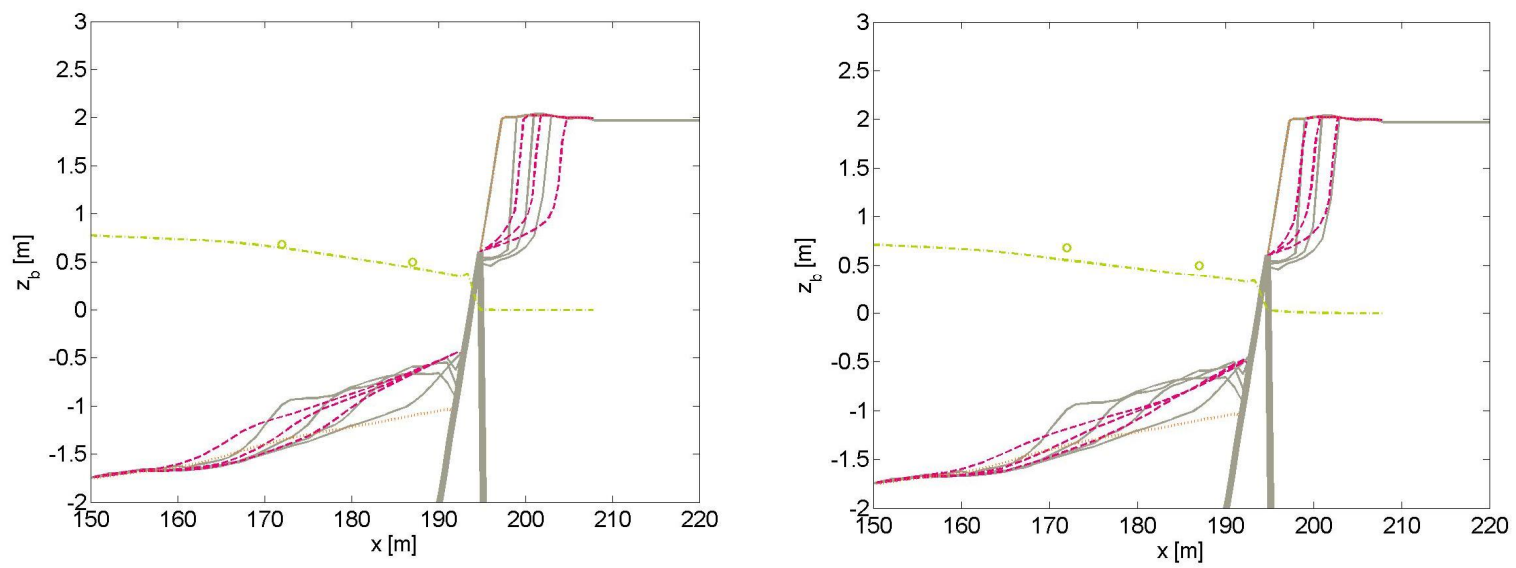

Figure 6: Measured (gray lines) and simulated (magnetta lines) profile evolution for default short wave dissipation formulation by Roelvink, 1993 (left panel) and an advective-deterministic approach to short wave breaking as proposed by Daly et al., 2011 (right panel).

\section{PROFILE WITHOUT REVETMENT}

So far it is shown that the updated XBeach model with short wave runup can be applied to simulate erosion above revetments in 1D flume tests. However, it has not been examined how the updated model performs on a classical sandy profile without revetment (dune erosion case). The 
hypothesis is that in these (typical XBeach) conditions the effect of short wave runup should be minimal since dissipative conditions are expected for a classical dune erosion case in which long wave variance dominates the near dune hydrodynamics and thus runup statistics.

To assess this in more detail an indicative simulation is conducted using the same profile as in tests T1-T3 but now applying a fully sandy profile (no revetment). Figure 7 shows the simulated runup statistics for the updated model (upper panels) and shows the simulated profile evolution, that is compared to the final profile simulated with original XBeach model without short wave runup (lower panel). It is found that in the initial phase of the simulation (upper left panel) both short waves and long waves contribute to the total runup statistics, but the long wave runup is relatively more important. Later in the simulation (upper right) the contribution of short waves to the total runup vanishes and dune face morphodynamics are controlled by the long wave swash motions.

Finally, comparison of the simulated profile evolution (lower panel Figure 7) reveals that the updated model results in a comparable profile evolution w.r.t. the original Xbeach model. This is a satisfying result and allows extending the updated model to $2 \mathrm{DH}$ cases containing sandy dune areas and areas with revetments.
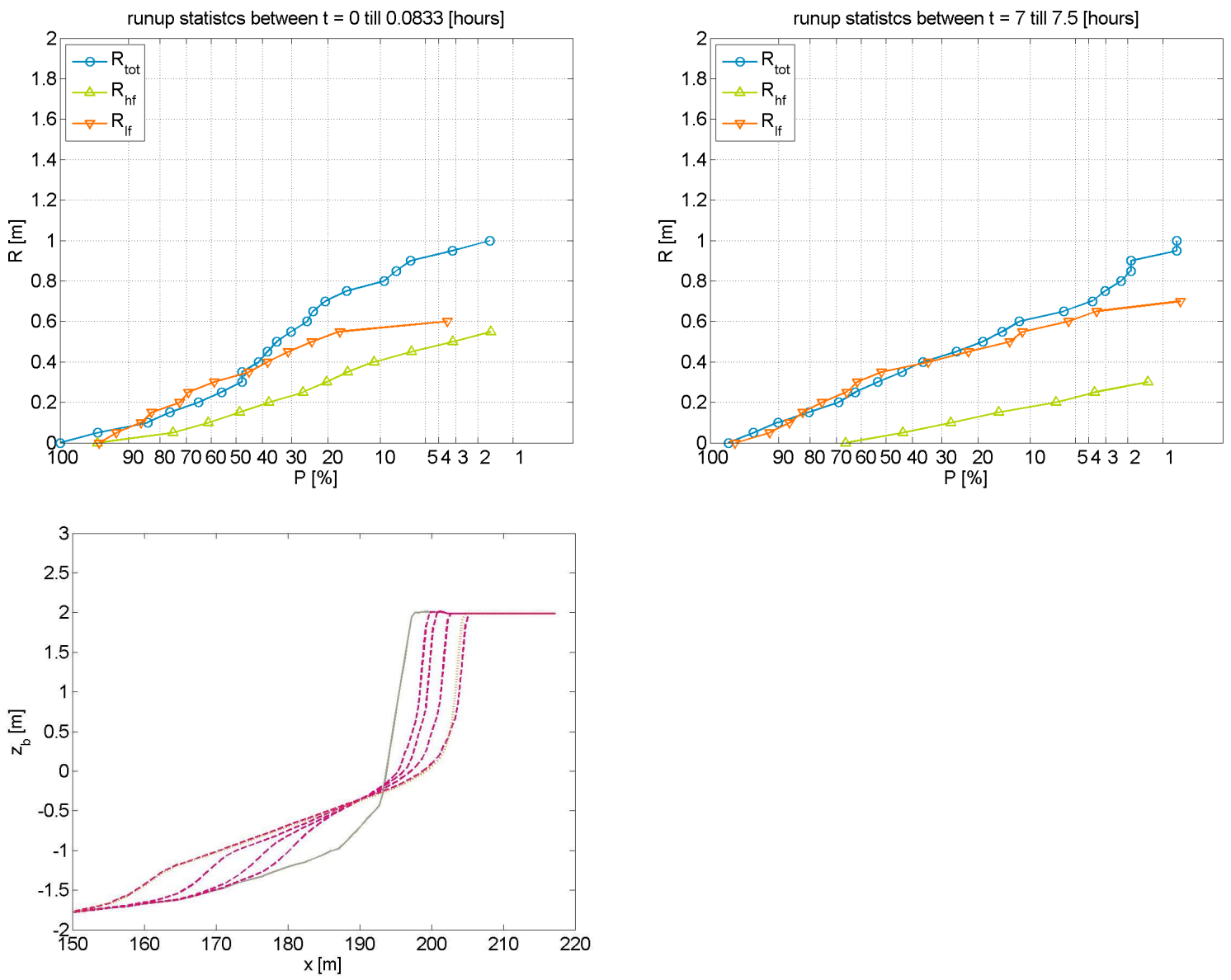

Figure 7: Upper panels: Simulated cumulative runup distributions during numerical test without revetment for short waves (green line), long waves (orange line) and total runup (blue line). Lower panel simulated profile evolution for profile without revetment for simulations including short wave runup (magnetta) and simulation without short wave runup (orange)

\section{SUMMARY AND CONCLUSIONS}

A research version of XBeach is presented wherewith the morphodynamics around a revetment can be assessed. It is found that to model dune erosion above revetments runup characteristics need to be predicted correctly. In the case of dune revetments these characteristics depend on both short waves and long waves. An updated version of the XBeach model is applied to a series of large scale flume tests in which revetments of different height are assessed. It is concluded that: 
1. The development of erosion above a dune revetment can be reasonably well modeled with a simple avalanching algorithm if the short wave runup distribution is included in the model

2. The scour pit development in front of a dune revetment is not well modeled. This is probably caused by some physical processes still missing in the model (see discussion section below).

3. Simulated runup statistics compare reasonably with available measurements and depend strongly on the short wave dissipation formulation that is applied.

4. Including short wave runup only slightly affects the simulated profile evolution for a classical sandy profile without a revetment since near dune hydrodynamics in these conditions are dominated by wave group generated long waves.

\section{DISCUSSION}

Scour hole development in front of a dune revetment is underestimated with the model for all simulations discussed in this paper. Looking at the physical processes, which are expected to influence the scouring in front of the structure most are incorporated in the model. The revetment has (implicitly the right location with respect to the wave break point. Also wave breaking intensity is accounted for and wave breaking induced turbulence can reach the bed and stir up sediment. The sediment properties are input to the sediment transport formulations applied in the model. The missing scouring processes are therefore hypothesized to be related to wave reflections, vertical rundown momentum that is not accounted for in the model and the increase in roughness from the sand bed towards the revetment which will influence turbulence generation.

The long wave reflections are solved for with the NSWE and therefore reflections will be solved for. The short wave transformation is obtained from a wave action balance that does not account for reflections. Short wave reflections will cause a standing wave pattern in the vicinity of the revetment, which will influence the cross-shore distribution of the orbital velocity and undertow. The standing wave pattern will locally enhance the variance in the orbital flow causing larger sediment suspensions. In addition the return flow in front of a revetment will decrease due to (short) wave reflections since the net onshore mass flux of the incoming short waves will partly be compensated by the mass flux of reflected short waves.

When waves runup the protected dune face and partly overtop it there is a rapid conversion from kinetic energy to potential energy. The water mass will slow down and eventually flow back as a result of gravity. The resulting backwash velocities can be high and the (super critical) water mass can be injected in the water column in front of the revetment. Depending on the penetration depth of this backwash jet a scour hole can develop.

\section{REFERENCES}

Battjes, J.A., 1974. Computation of Set-Up, Longshore Currents, Runup and Overtopping Due to Wind-Generated Waves, PhD Thesis, Delft University of Technology, The Netherlands. 244 pp.

Battjes, J.A., 1974. Surf similarity, 14th International Conference on Coastal Engineering, Copenhagen, pp. 466-477.

Battjes, J.A. and M.J.F. Stive, 1985, Calibration and verification of a dissipation model for random breaking waves, Journal of Geophysical Research, 90 (C5), 9159-9167.

Daly Christopher, Dano Roelvink, Ap van Dongeren, Jaap van Thiel de Vries, Robert McCall, Validation of an advective-deterministic approach to short wave breaking in a surf-beat model, Coastal Engineering, Volume 60, February 2012, Pages 69-83, ISSN 0378-3839, 10.1016/j.coastaleng.2011.08.001.

De Vries, B, Van Dongeren, A., Van Thiel de Vries, J., Van Geer, P., 2012. Dune erosion near sea walls: model-data comparison, International Confrenece on Coastal Engineering, 2012, Santander, Spain.

Fisher, J.S. and Overton, M.F., 1984. Numerical model for dune erosion due to wave uprush, 19th International Conference on Coastal Engineering, Houston, pp. 1553-1558.

Larson, M., Erikson, L. and Hanson, H., 2004a. An analytical model to predict dune erosion due to wave impact. Coastal Engineering, 51(8-9): 675-696.

Nishimura, H., Waranoke, A. and Horikawa, K. (1978) Scouring at the toe of a seawall due to tsunamis. Proc. 16th Coastal Engineering Conference, Hamburg, Germany, ASCE 2540-2547. 
Margaret L. Palmsten, Robert A. Holman, Laboratory investigation of dune erosion using stereo video, Coastal Engineering, Volume 60, February 2012, Pages 123-135, ISSN 0378-3839, 10.1016/j.coastaleng.2011.09.003.

Dano Roelvink, Ad Reniers, Ap van Dongeren, Jaap van Thiel de Vries, Robert McCall, Jamie Lescinski, Modelling storm impacts on beaches, dunes and barrier islands, Coastal Engineering, Volume 56, Issues 11-12, November-December 2009, Pages 1133-1152, ISSN 0378-3839, 10.1016/j.coastaleng.2009.08.006.

Roelvink, J.A., 1993. Surf beat and its effect on cross-shore profiles. PhD thesis, Delft University of Technology, Delft, The Netherlands.

Saville, T., 1962, An approximation of the wave runup frequency distribution Proc. Conf. on Coastal Eng., $8^{\text {th }}$, Mexico (1962).

Steetzel, H.J., 1987. Systematic reserach on the effectiveness of dune toe revetments, Large scale model investigation (in Dutch), Report H298-I, Delft Hydraulics, Delft, The Netherlands.

Sumer, B. M, Fredsøe, J., 2002. The Mechanics of Scour in the Marine Environment - World Scientific in: Advanced Series on Ocean Engineering, Volume 17. Book.

TAW: 2002 Technical Report - Wave runup and wave overtopping at dikes. Technical

Advisory Committee for Flood Defence in the Netherlands (TAW). Delft.

Van Dongeren, A., Reniers, A., Battjes, J., Svendsen, I., 2003. Numerical modeling of infragravity wave response during DELILAH. J. Geophys. Res. 108 (C9), 3288. doi:10.1029/2002JC001332.

Van Gent, M.R.A., Van Thiel de Vries, J.S.M., Coeveld, E.M., De Vroeg, J.H. and Van de Graaff, J., 2008. Large-scale dune erosion tests to study the influence of wave periods. Coastal Engineering, 55(12): 1041-1051.

Van Thiel de Vries, J.S.M., Van de Graaff, J., Raubenheimer, B., Reniers, A.J.H.M. and Stive, M.J.F., 2006. Modeling inner surf hydrodynamics during storm surges, 30th International Conference on Coastal Engineering, San Diego, USA, pp. 896-908.

Van Thiel de Vries, J.S.M., Clarke, L.B., Aarninkhof, S.G.J., Coeveld, E.M., Holman, R.A., Palmsten, M.L., Reniers, A.J.H.M., Stive, M.J.F. and Uijttewaal, W.S.J., 2007. Interaction of dune face and swash zone, Coastal Sediments, New Orleans, pp. 1975-1987. 